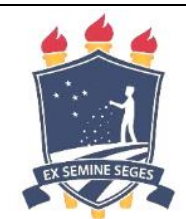

\title{
Avaliação clínica de linfonodos superficiais de pequenos ruminantes criados no estado de Sergipe, Brasil
}

\author{
[Clinical evaluation of superficial lymph nodes in small ruminants bred in the State of Sergipe, Brazil]
}

\section{"Artigo Científico/Scientific Article"}

\author{
Huber Rizzo $^{1,2 *}$, Jeferson Silva Carvalho $^{2}$, Nilton Souza Santos Júnior ${ }^{3}$, Taile Katiele Souza Jesus ${ }^{2}$, Carlos \\ Milton Mendonça Tourinho Júnior ${ }^{3}$, Demetro Dantas Reis ${ }^{4}$, Fábio Franco Almeida ${ }^{5}$, \\ Marcos Vinícius Ferreira Magalhães ${ }^{6}$, Cícero Estrela Farias ${ }^{7}$, Ramón Andrade Coelho ${ }^{8}$, \\ Tatiane Rodrigues Silva ${ }^{9}$
}

\footnotetext{
${ }^{1}$ Departamento de Medicina Veterinária, Universidade Federal Rural de Pernambuco, Recife-PE, Brasil.

${ }^{2}$ Programa de Pós-Graduação em Ciência Veterinária, Universidade Federal Rural de Pernambuco, Recife-PE, Brasil.

${ }^{3}$ Médico veterinário autônomo, Aracaju-SE, Brasil.

${ }^{4}$ AgroNordeste Agricultura e Veterinária, Cícero Dantas-BA, Brasil.

${ }^{5}$ Clínica Médica e Cirúrgica de Grandes Animais, Universidade Federal Rural do Semiárido, Mossoró-RN, Brasil.

${ }^{6}$ Programa de Pós-Graduação em Ciências Fisiológicas, Universidade Federal de Sergipe, São Cristovão-SE, Brasil.

${ }^{7}$ Departamento de Medicina Veterinária, Universidade Federal de Sergipe, São Cristovão-SE, Brasil.

${ }^{8}$ Animal Pat Lab Exames Laboratoriais Veterinários, Aracaju-SE, Brasil.

${ }^{9}$ Centro de Saúde e Tecnologia Rural, Universidade Federal da Campina Grande, Patos-PB, Brasil.

*Autor para correspondência/Corresponding author: E-mail: hubervet@gmail.com
}

\begin{abstract}
Resumo
O objetivo do estudo foi determinar a ocorrência e distribuição topográfica de linfonodos superficiais com alterações clínicas (hiperplasias, abscessos e/ou feridas em processo de cicatrização), sugestivas de Linfadenite Caseosa (LC), em pequenos ruminantes criados no estado de Sergipe. Entre os anos de 2011 e 2014, foram realizados exames clínicos de 1.908 pequenos ruminantes de 101 propriedades, inspeção e palpação de linfonodos superficiais, além do isolamento bacteriano de vinte amostras de secreções extraídas dos abscessos intactos. A ocorrência de animais com alterações macroscópicas em linfonodos superficiais foi de 7,18\% (137/1908), sendo 5,19\% (64/1.231) em ovinos e 10,8\% (73/677) nos caprinos ( $\mathrm{p}<0,001)$, acometendo 172 linfonodos. Dentre eles, 33,72\% (58) eram o préescapular, $27,34 \%$ (47) submandibular, $15,11 \%$ (26) retromamário, $10,46 \%$ (18) pré-crural, 5,81\% (10) parotídeo, $4,07 \%$ (7) retrofaríngeo, $1,16 \%$ (2) cervical profundo médio e caudal e $0,58 \%$ (1) cervical cranial e poplíteo. As regiões do tronco e posterior do corpo foram as que concentraram maior número de linfonodos alterados. Todas as amostras submetidas ao isolamento apresentaram crescimento de Corynebacterium pseudotuberculosis. A presença de animais, com sinais clínicos de LC, atenta para a necessidade da adoção de medidas profiláticas para controle da doença nos rebanhos sergipanos.
\end{abstract}

Palavras-Chave: abscesso, Corynebacterium pseudotuberculosis, linfadenite caseosa.

\begin{abstract}
The aim of the study was to determine the occurrence and topographic distribution of lesions suggestive of Caseous Lymphadenitis (CL) (abscesses, hyperplasia and/or wounds in cicatrization process) in superficial lymph nodes of the small ruminants bred in the state of Sergipe. Between years 2011 and 2014, were made clinical examinations of 1.908 small ruminants of 101 properties of the state, inspection and palpation of the superficial lymph nodes region. Bacterial isolation was realized on twenty samples of secretions of abscesses extract intact. The occurrence of animals with macroscopic lesions in lymph was $7.18 \%$ (137/1908), 5.19\% (64/1,231) in sheep and 10.8\% (73/677) in goats $(\mathrm{p}<0,001)$, affecting 172 lymph nodes. The topographic distribution of altered lymph nodes was $33.72 \%$ (58) in the prescapular, $27.34 \%$ (47) in the submandibular, $15.11 \%$ (26) in mammary, $10.46 \%$ (18) crural, $5.81 \%$ (10) in the parotid, $4.07 \%$ (7) retropharyngeal, $1.16 \%$ (2) in the middle deep cervical and caudal and 0,58\% (1) in the cranial cervical and popliteal. The trunk and posterior regions of the body were concentrated greater numbers of altered nodes. All samples submitted to bacterial isolation were positive for Corynebacterium pseudotuberculosis. The breeders should be aware of prophylactic measures of CL, and the presence of an infected animal can serve as a source of dissemination of the disease in the herd.
\end{abstract}

Key-words: abscess, Corynebacterium pseudotuberculosis, caseous lymphadenitis. 


\section{Introdução}

Nos rebanhos de pequenos ruminantes, é frequente a presença de animais com abscessos nos gânglios do sistema linfático subcutâneo e visceral, geralmente causado pelo Corynebacterium pseudotuberculosis, agente etiológico da Linfadenite Caseosa (LC) ou "mal do caroço", que gera prejuízos significativos (Machado et al., 2011), pela condenação de vísceras, carcaças, perda na qualidade do couro e lã, podendo ainda levar o animal a um estado de imunossupressão e/ou doença crônica chegando ao óbito principalmente ao atingir órgãos vitais como pulmões, fígado, rins (Brown e Olander, 1987; Belchior et al., 2006; Souza et al., 2011) e medula (Rizzo et al., 2014). Outras alterações clínicas observadas são a anemia, leucocitose com neutrofilia, hiperfibrinogenemia, hipoproteinemia ou hiperproteinemia por aumento de globulinas, principalmente IgG, e elevação do interferon gama (IFN-g) (Belchior et al., 2006).

O rompimento natural desses abscessos no ambiente, exerce fator de risco importante da disseminação do C. pseudotuberculosis a animais sadios, além de contaminar pastagens, instalações e utensílios (Brown e Olander, 1987; Belchior et al., 2006). O agente possui também relevância zoonótica, principalmente devido à exposição ocupacional, e de saúde pública, pois tem caráter de diagnóstico diferencial para a tuberculose (Machado et al., 2011; Andrade et al., 2012).

O intenso mercado, a circulação de pequenos ruminantes sem as medidas de biossegurança e o uso coletivo de reprodutores (Rizzo et al., 2014), associado a falhas de manejo sanitário em algumas propriedades do Nordeste tornam-se obstáculos importantes para o controle da LC, mantendo a sua ocorrência em níveis elevados (Guimarães et al., 2011; Teixeira et al., 2015), com evidências da doença em todos os estados da região (Moura Costa et al., 1973; Lima et al., 2005; Coelho et al., 2011; Nascimento et al., 2011; Andrade et al., 2012; Jabour, 2013; Santos et al., 2013; Rizzo et al., 2014; Teixeira et al., 2015).

O diagnóstico presuntivo de infecção baseiase na palpação dos linfonodos superficiais aumentados, características macroscópicas de exsudato, sinais clínicos, como febre ou perda de peso e dados epidemiológicos da prevalência local e idade do animal. O diagnóstico definitivo é realizado pelo cultivo do microrganismo, a partir de secreção obtida dos abscessos, onde à coloração de Gram observa-se formas cocobacilares
(Chirino-Zárraga et al., 2006). Pode-se ainda realizar exames citológicos, histológicos, sorológicos e de biologia molecular para o diagnóstico da LC (Belchior et al., 2006, Souza et al., 2011).

O objetivo do trabalho foi relatar a ocorrência e a distribuição topográfica de linfonodos superficiais com alterações clínicas (hiperplasias, abscessos e/ou feridas em processo de cicatrização), sugestivas de LC, em pequenos ruminantes criados no Estado de Sergipe, Brasil.

\section{Material e Métodos}

O estudo foi realizado no estado de Sergipe (latitude $9^{\circ} 30^{\prime} 49^{\prime \prime}$ e $11^{\circ} 34^{\prime} 05^{\prime \prime}$ e longitude $36^{\circ}$ $23^{\prime} 40^{\prime \prime}$ e $\left.38^{\circ} 15^{\prime} 00^{\prime \prime}\right)$, localizado na região Nordeste do Brasil, com área de $21.910 \mathrm{~km}^{2}$, divididos em 75 municípios distribuídos em três mesorregiões: leste, agreste e sertão (IBGE, 2015). Foram examinados entre os anos de 2011 e 2014, 1.908 pequenos ruminantes, 1.231 ovinos e 677 caprinos, de 101 propriedades localizadas em 25 municípios das três mesorregiões do estado. O número de propriedades visitadas e animais examinados foram, respectivamente, para as mesorregiões leste, agreste e sertão sergipano de 44 e 882,30 e 520 e 27 e 506 (Figura 1).

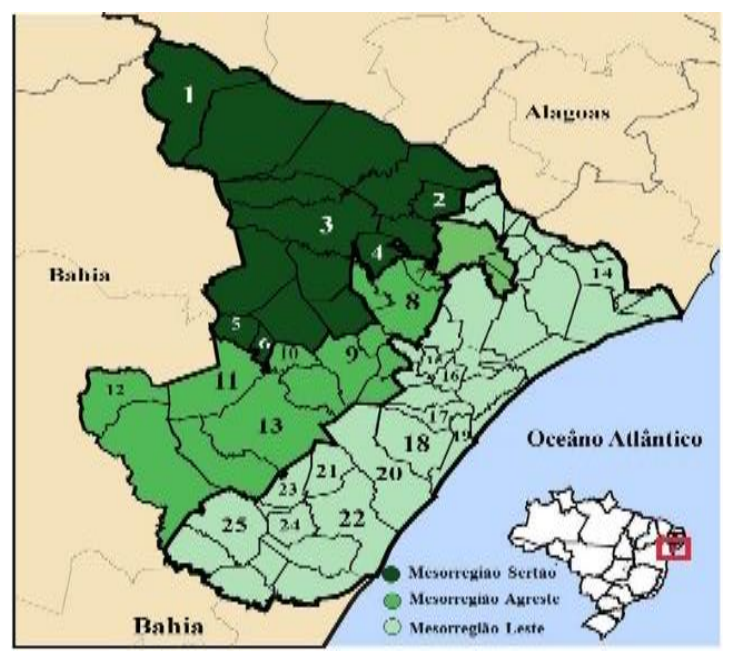

Figura 1. Mapa de Sergipe dividido em suas três mesorregiões indicando numericamente os municípios dos rebanhos de pequenos ruminantes examinados. Mesorregião sertão: 1Canindé de São Francisco, 2-Itabi, 3-Nossa Senhora da Glória, 4-Feira Nova, 5-Pinhão e 6-Pedra Mole. Mesorregião agreste: 7-Cumbe 8-Nossa Senhora das Dores, 9-Itabaiana, 10-Macambira, 11-Simão Dias, 12 Poço Verde e 13-Lagarto. Mesorregião leste: 14-Neópolis 15-Divina Pastora, 16-Maruim, 17- Nossa Senhora do Socorro, 18- São Cristóvão, 19-Aracaju, 20-Itaporanga D'Ajuda, 21-Salgado, 22-Estância, 23-Boquim, 24-Arauá e 25-Itabaianinha (IBGE, 2014). 
A escolha dos municípios e das propriedades foi realizada de acordo com a divisão do estado, conveniência, facilidade de acesso e disponibilidade dos produtores. Foram examinados de sete a 22 pequenos ruminantes por propriedade, selecionados aleatoriamente, entre diferentes padrões zootécnicos, de raças puras (AngloNubiana, Bôer, Dorper, Pardo Alpina, Saanen, Santa Inês e Toggenburg) mestiças e sem raça definida, aparentemente hígidos, com idade superior a seis meses.

O exame físico foi realizado por meio da inspeção e palpação, principalmente das regiões onde se localizam os linfonodos superficiais (parotídeos, submandibulares, retrofaríngeos, préescapulares, pré-crurais, retromamários e poplíteos), a fim de identificar lesões sugestivas de LC, tais como hiperplasia ou abscesso de consistência flutuante ou não, supuração de material caseoso e/ou ferida em processo de cicatrização. Nos animais onde foram identificadas as alterações, os linfonodos eram palpados na intenção de analisar sua mobilidade, temperatura e consistência, além de ser pesquisada a presença de algum indício de processo inflamatório ou infecioso na região corpórea correspondente por sua drenagem linfática (Pugh, 2005).

Todos os linfonodos hiperplásicos/abscessos e/ou feridas em processo de cicatrização foram fotografados para posterior conferência de sua nomenclatura e classificação de acordo com sua posição topográfica dividida quanto a área: cabeça, pescoço, tronco (tórax e abdômen) e membros, assim como quanto aos antímeros (esquerdo e direito) e regiões (posterior e anterior) do corpo (Getty, 1981). Em todas as propriedades visitadas, foi aplicado questionário epidemiológico, aos produtores, a fim de avaliar as características e o manejo da propriedade.

O diagnóstico, pelo isolamento bacteriano, foi realizado por amostragem onde colheu-se aleatoriamente dez amostras de cada espécie, de distintas propriedades. A colheita do material foi realizada, com antissepsia prévia da região utilizando álcool iodado a 70\%, seguida de incisão do linfonodo com lâmina de bisturi estéril. O conteúdo do seu interior foi armazenado em potes plásticos estéreis, identificados e transportados sob refrigeração até o laboratório Animal PatLab, Aracaju, Sergipe. As amostras colhidas dos linfonodos foram semeadas em meio contendo ágar sangue de carneiro a 5\%, incubados por 24 horas a temperatura de $37^{\circ} \mathrm{C}$. Após esse período foi realizado a observação das colônias para posterior realização do Gram e identificação bioquímica para a confirmação do gênero e espécie (Winn et al., 2008).

A distribuição da ocorrência de animais com presença ou ausência de lesões sugestivas de LC em linfonodos superficiais foi associada estatisticamente com as variáveis espécie animal, antímero e região do corpo através do teste quiquadrado com $5 \%$ de significância, utilizando software graphpad instat 3.1 .

\section{Resultados}

A ocorrência de pequenos ruminantes que apresentaram linfonodos hiperplásicos, abscessos e/ou feridas em processo de cicatrização em regiões de linfonodos superficiais foi de 7,18\% (137/1908), sendo 5,19\% (64/1231) dos ovinos e $10,78 \%$ (73/677) dos caprinos $(\mathrm{p}<0,001)$. Em $55,44 \%$ (56/101) das propriedades, 58,33\% (35/60) ovinas e $63,41 \%(26 / 41)$ caprinas, havia pelo menos um animal com linfonodo alterado (Tabela $1)$.

Não foi observado no exame clínico geral dos 137 animais evidencias físicas de infecções e/ou inflamações na região na qual o linfonodo hiperplásico era responsável pela drenagem linfática. O número de linfonodos hiperplásicos, abscessos e/ou feridas em processo de cicatrização observados foi de 172, variando de um a quatro no mesmo animal com média de 1,24 , sendo a grande maioria $(78,83 \%)$ com apenas um linfonodo acometido no momento do exame (Tabela 2).

A ocorrência dos linfonodos acometidos de alterações clínicas estão descritos na Tabela 3 e ilustrado na Figura 2, sendo o mais afetado o préescapular seguido do submandibular.

Ao serem agrupados segundo a região topográfica corpórea, as que apresentaram maior quantidade de linfonodos alterados foram: do tronco, (linfonodos pré-escapulares, pré-crurais e retromamários) e cabeça (linfonodos submandibulares, parotídeos e retrofaríngeos) seguido por pescoço (linfonodos cervicais) e membros (linfonodo poplíteo) (Tabela 4). 


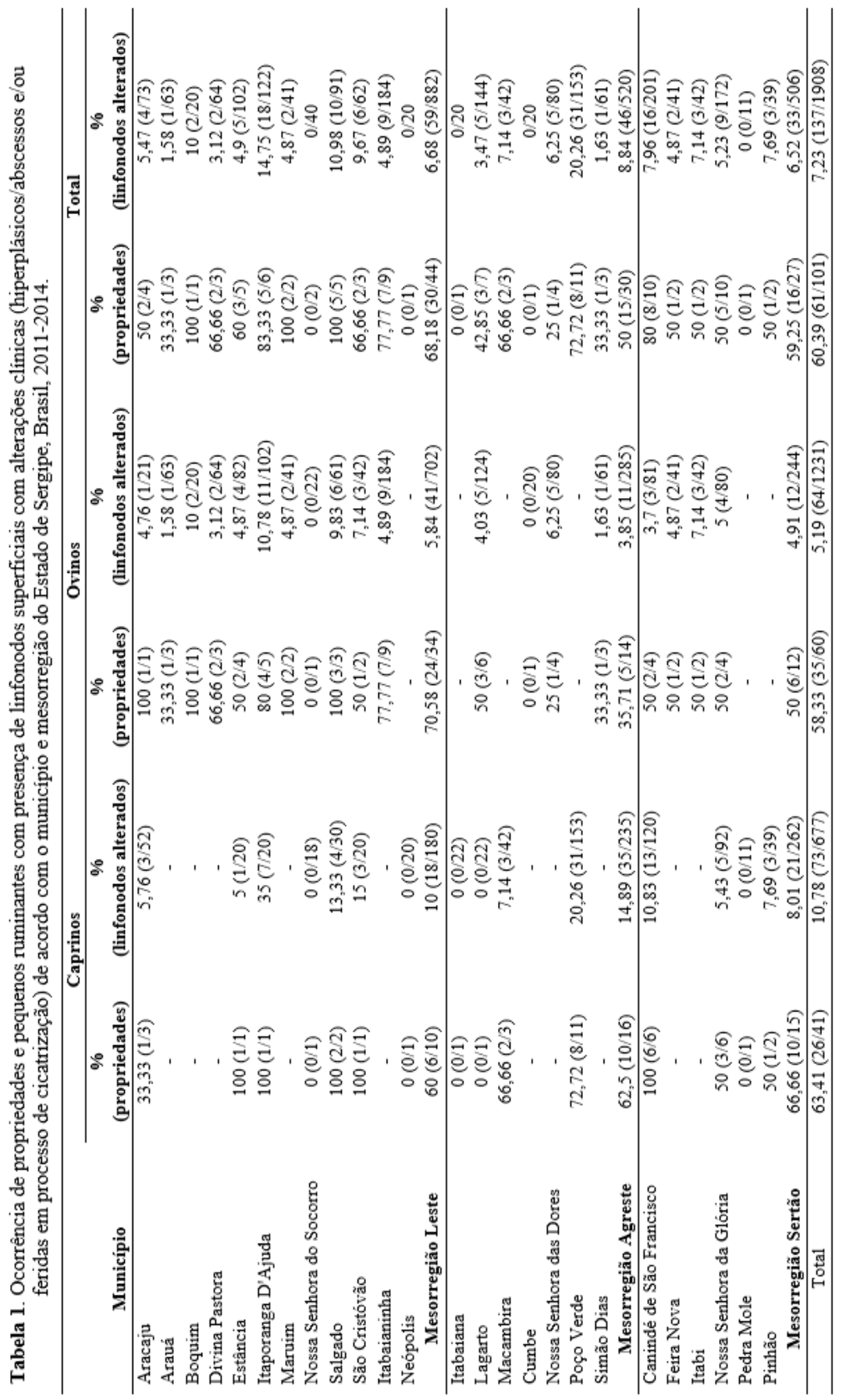


Tabela 2: Quantidade de linfonodos superficiais com alterações clínicas (hiperplásicos/abscessos e/ou feridas em processo de cicatrização) presentes simultaneamente em 137 pequenos ruminantes criados no Estado de Sergipe, Brasil 2011-2014.

\begin{tabular}{|c|c|c|c|c|c|}
\hline \multirow[b]{2}{*}{ Espécie } & \multicolumn{4}{|c|}{ Número de linfonodos com alterações macroscópicas (\%) } & \multirow[t]{2}{*}{ Total $(\%)$} \\
\hline & 1 & 2 & 3 & 4 & \\
\hline Caprina & $55(40,14)$ & $16(11,67)$ & $2(1,46)$ & - & $93(54,07)$ \\
\hline Ovina & $53(38,68)$ & $8(5,85)$ & $2(1,46)$ & $1(0,74)$ & $79(45,93)$ \\
\hline Total de linfonodos & $108(62,79)$ & $48(27,91)$ & $12(6,98)$ & $4(2,32)$ & $172(100)$ \\
\hline Total de animais & $108(78,83)$ & $24(17,52)$ & $4(2,91)$ & $1(0,74)$ & $137(100)$ \\
\hline
\end{tabular}

Tabela 3: Ocorrência e distribuição dos linfonodos superficiais com alterações clínicas em pequenos ruminantes criados no Estado de Sergipe, Brasil, 2011-2014.

\begin{tabular}{lccccccc}
\hline \multirow{2}{*}{ Linfonodos } & \multicolumn{3}{c}{ Caprinos (\%) } & \multicolumn{3}{c}{ Ovinos (\%) } & Total \\
\cline { 2 - 8 } & Direito & Esquerdo & Total & Direito & Esquerdo & Total & Linfonodo (\%) \\
\hline Pré-escapular & $15(8,72)$ & $18(10,46)$ & $33(19,18)$ & $15(8,72)$ & $10(5,81)$ & $25(14,53)$ & $58(33,72)$ \\
Submandibular & $19(11,04)$ & $18(10,46)$ & $37(21,51)$ & $5(2,91)$ & $5(2,91)$ & $10(5,81)$ & $47(27,34)$ \\
Retromamário & $5(2,91)$ & $4(2,32)$ & $9(5,23)$ & $6(3,48)$ & $11(6,39)$ & $17(9,88)$ & $26(15,11)$ \\
Pré-cural & $7(4,07)$ & - & $7(4,07)$ & $6(3,48)$ & $5(2,91)$ & $11(6,39)$ & $18(10,46)$ \\
Parotídeo & $5(2,91)$ & $2(1,16)$ & $7(4,07)$ & $1(0,58)$ & $2(1,16)$ & $3(1,74)$ & $10(5,81)$ \\
Retrofaríngeo & - & - & - & $4(2,32)$ & $3(1,74)$ & $7(4,07)$ & $7(4,07)$ \\
$\begin{array}{l}\text { Cervical profundo } \\
\text { médio }\end{array}$ & - & - & - & - & $2(1,16)$ & $2(1,16)$ & $2(1,16)$ \\
$\begin{array}{l}\text { Cervical profundo } \\
\text { caudal }\end{array}$ & - & - & - & $2(1,16)$ & - & $2(1,16)$ & $2(1,16)$ \\
Cervical cranial & - & - & - & $1(0,58)$ & - & $1(0,58)$ & $1(0,58)$ \\
$\begin{array}{l}\text { Poplíteo esquerdo } \\
\text { Total por espécie }\end{array}$ & $51(29,65)$ & $42(24,41)$ & $93(54,07)$ & $40(23,25)$ & $38(22,09)$ & $79(45,93)$ & $172(100)$
\end{tabular}
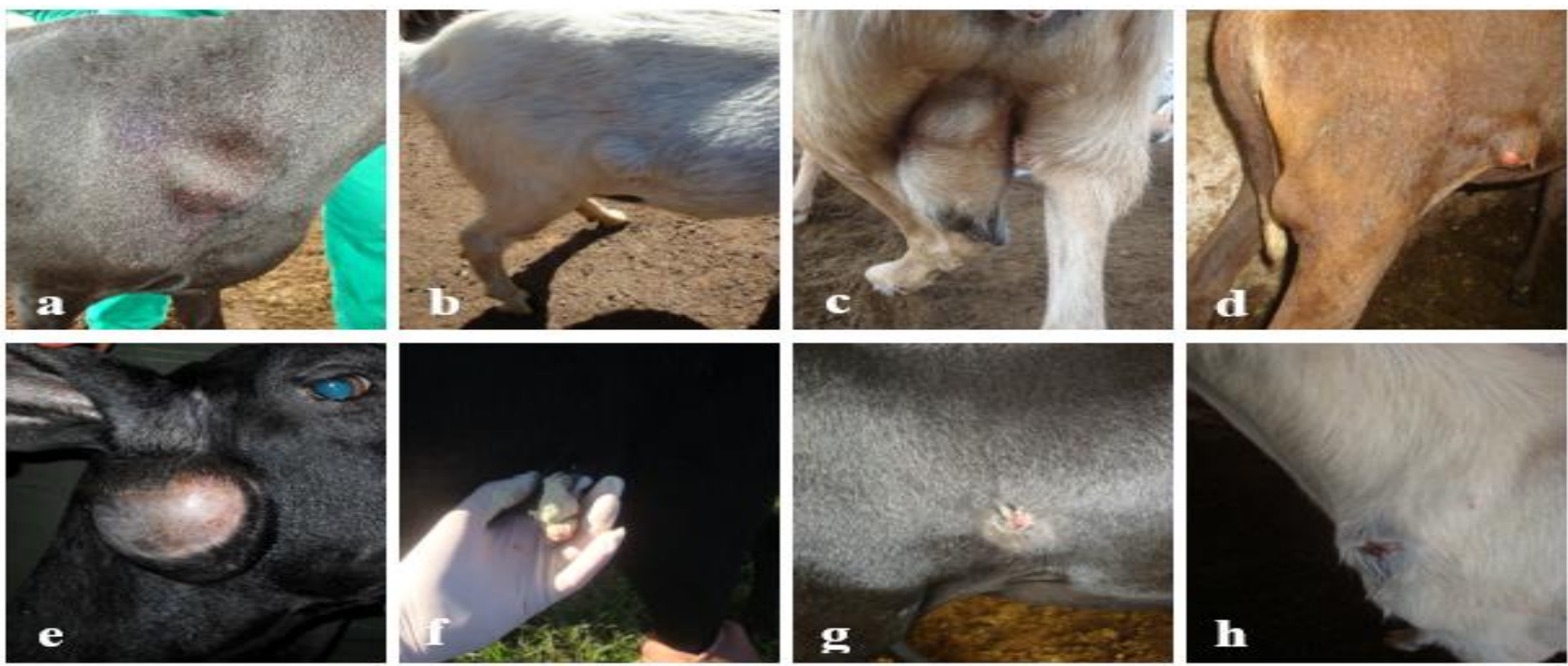

Figura 2: Principais linfonodos superficiais acometidos após levantamento em caprinos e ovinos criados no Estado de Sergipe. Linfonodos (a) préescapular direito em ovino, (b) pré-crural direito em caprino, (c) retromamário esquerdo em caprino, (d) poplíteo e pré-crural direito em ovino apresentando aumento de volume, (e) linfonodo parotídeo em ovino apto para drenagem apresentando consistência flutuante, espessura de pele reduzida e ausência de pelos, (f) material caseoso drenado de linfonodo pré-crural esquerdo de ovino, (g) feridas em processo de cicatrização em região de linfonodos pré-crural direito de ovino e (h) pré-escapular esquerdo de caprino. 
Tabela 4: Ocorrência de linfonodos superficiais com alterações clínicas segundo a região corpórea em pequenos ruminantes criados no estado de Sergipe, Brasil, 2011-2014.

\begin{tabular}{|c|c|c|c|}
\hline \multirow[b]{2}{*}{ Região corpórea } & \multicolumn{2}{|c|}{ Espécie } & \multirow[b]{2}{*}{ Total $(\%)$} \\
\hline & Caprino (\%) & Ovino (\%) & \\
\hline Tronco & $49(28,48)$ & $53(30,81)$ & $102(59,30)$ \\
\hline Cabeça & $44(25,58)$ & $20(11,62)$ & $64(37,21)$ \\
\hline Pescoço & - & $5(2,91)$ & $5(2,91)$ \\
\hline Membros & - & $1(0,58)$ & $1(0,58)$ \\
\hline Total por espécie & $93(54,07)$ & $79(45,93)$ & $172(100)$ \\
\hline
\end{tabular}

Em relação aos antímeros esquerdo e direito do corpo, os valores não diferiram com $47,09 \%$ $(81 / 172)$ e $52,91 \%$ (91/172) respectivamente $(\mathrm{p}=0,5174)$, já ao avaliarmos em relação à região anterior $(73,84 \%, 127 / 172)$ e posterior $(26,16 \%$, 45/172) observa-se diferença significante $(\mathrm{p}<0,001)$.

A drenagem do conteúdo dos linfonodos que se apresentavam "maduros" ocorreu em 55,23\% (95/172) deles, sempre com presença de secreção amarelo-esverdeado ou branco-amarelado de consistência variando de purulenta a caseosa
(Brown e Olander, 1987; Belchior et al., 2006). Em $35,46 \%$ (61/172) dos casos os mesmo não se encontravam aptos a serem drenados devido à consistência firme e outros 9,31\% (16/172) eram feridas em processo de cicatrização em região de linfonodos superficiais.

As vinte amostras submetidas ao isolamento bacteriano, apresentaram no cultivo em placa de ágar-sangue ovino, colônias pequenas, secas e acinzentadas. $\mathrm{Na}$ microscopia observou-se bactérias de morfologia coco bacilos Gram + características de C. pseudotuberculosis (Figura 3).

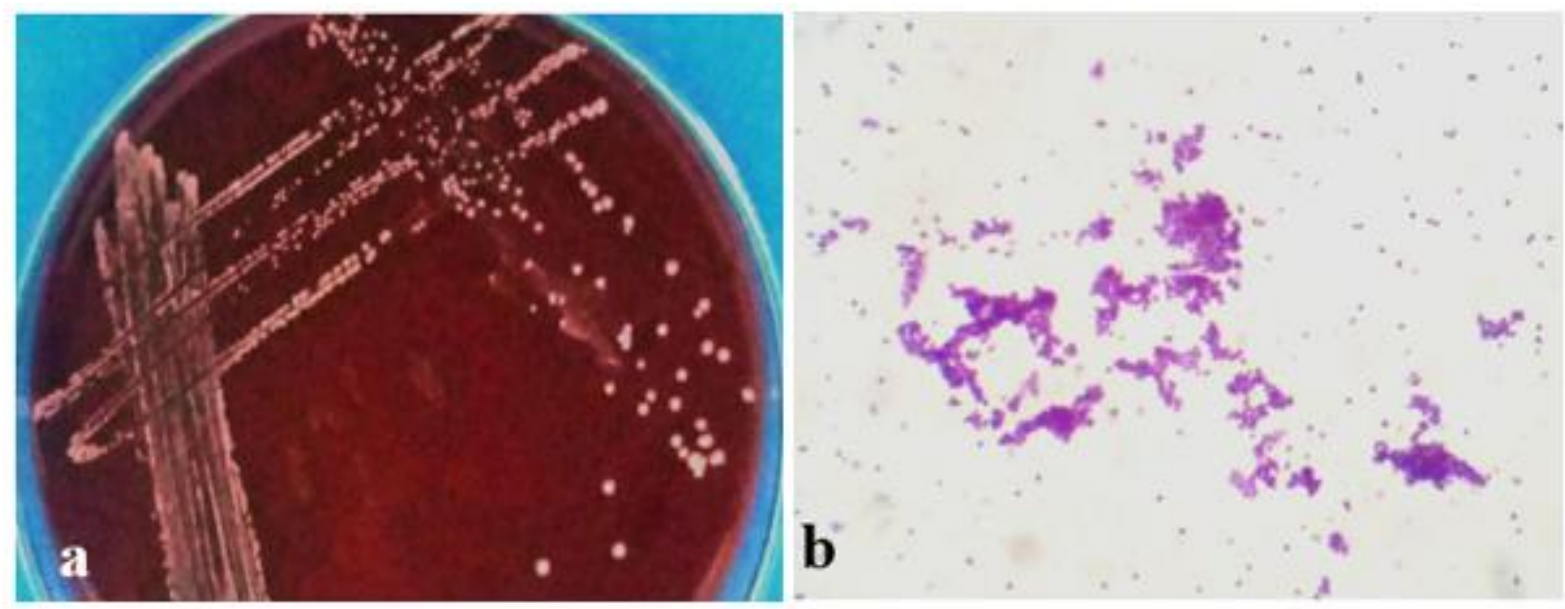

Figura 3: Diagnóstico bacteriológico através do isolamento de C. pseudotuberculosis, sendo; (a) cultivo em placa de ágar-sangue ovino demonstrando colônias pequenas, secas e acinzentadas e (b) apresentação microscópica de bactérias de morfologia coco bacilos gram + características de C. pseudotuberculosis.

Sobre às características das propriedades, 0 sistema de criação semiextensivo, onde os animais eram contidos em aprisco durante a noite, foi o predominante $(58,41 \%)$, e os fatores que se mostraram mais relevantes para a disseminação da LC foram à baixa adoção da quarentena $(37,62 \%)$ e a não desinfecção das instalações $(62,38 \%)$.
Outras falhas de manejo também se mostraram presentes como pastejo comunal entre rebanhos, contato entre animais saudáveis e enfermos, utilização e empréstimos de reprodutores de outras propriedades, principalmente entre os rebanhos caprinos (Tabela. 5). 
Tabela 5: Características de criação de 101 propriedades de pequenos ruminantes do Estado de Sergipe, Brasil, 2011 2014.

\begin{tabular}{|c|c|c|c|}
\hline Características das propriedades & $\begin{array}{c}\% \\
\text { (propriedades caprinos) } \\
n=41\end{array}$ & $\begin{array}{c}\% \\
\text { (propriedades ovinos) } \\
\mathbf{n}=\mathbf{6 0}\end{array}$ & $\begin{array}{c}\% \\
\text { Total } \\
(\mathbf{n}=\mathbf{1 0 1}) \\
\end{array}$ \\
\hline \multicolumn{4}{|l|}{ Regime de criação } \\
\hline Intensivo & $19,51(8)$ & $5(3)$ & $10,89(11)$ \\
\hline Semiextensivo & $65,85(27)$ & $53,33(32)$ & $58,41(59)$ \\
\hline Extensivo & $14,64(6)$ & $41,67(25)$ & $30,7(31)$ \\
\hline Não utiliza quarentena & $58,54(24)$ & $65(39)$ & $62,38(63)$ \\
\hline Não desinfeta instalações & $78,05(32)$ & $51,67(31)$ & $62,38(63)$ \\
\hline Há contato entre animais saudáveis e enfermos & $63,41(26)$ & $41,67(25)$ & $50,49(51)$ \\
\hline Utiliza reprodutores de outras propriedades & $39,02(16)$ & $16,67(10)$ & $25,74(26)$ \\
\hline Empresta reprodutores a outras propriedades & $31,7(13)$ & $18,33(11)$ & $23,76(24)$ \\
\hline Pastejo comunal com outros criadores & $21,95(9)$ & $8,33(5)$ & $13,86(14)$ \\
\hline
\end{tabular}

\section{Discussão}

A ocorrência de linfonodos superficiais com alterações clínicas em caprinos e ovinos, sugestivo da infecção por C. pseudotuberculosis, foi de $7,18 \% \quad(137 / 1908)$ dos animais examinados. Resultado semelhante foi encontrando na Paraíba, a partir de inspeção e palpação de linfonodos superficiais, onde $7,66 \%(49 / 640)$ apresentaram evidências clínicas de LC, sendo que 59,18\% (29/49) dos achados foram de cicatrizes devido abscessos e 40,81\% (20/49) de abscessos intactos, diferindo dos rebanhos sergipanos que apresentaram maior ocorrência de abscessos intactos (Andrade et al., 2012). Em um rebanho ovino, criado em Nossa Senhora das Dores, Sergipe, a ocorrência de animais com lesões foi de $8,93 \%$ (10/112) (Freitas et al., 2011), assemelhando-se a observada dentre os ovinos do estudo.

Estudo conduzido com ovinos deslanados abatidos no município de Mulungu, Paraíba, identificou 4,71\% (70/1486) de animais com lesões compatíveis com à LC no exame ante mortem (Souza et al., 2011). Índice superior foi observado em ovinos da raça Santa Inês de onze propriedades da região de Uberlândia, Minas Gerais, com ocorrência de 14,76\%, (96/650) de animais com ao menos um linfonodo reativo (Barbosa et al., 2012). Em ovinos abatidos no Rio Grande do Sul, a LC ocorreu em 0,037\% (348/932.547) das carcaças determinando a condenação total de 0,009\% (86/932.547) delas (Machado et al., 2011).

Segundo trabalho de Al-Gaabary et al. (2009), em duas províncias egípcias, foram identificados 23,33\% (228/977) de ovinos e $11,04 \%$ (59/489) de caprinos clinicamente afetados, diagnosticados com $C$. pseudotuberculosis em 94,73\% (216/228) e 70,3\% (38/54) das amostras respectivamente. Resultado que diverge desse estudo onde os caprinos apresentaram maior ocorrência de lesões que os ovinos $(\mathrm{p}<0,001)$ provavelmente devido ao maior número de propriedades com falhas de manejo como demonstra a Tabela 4. Na Nova Zelândia (Nuttall et al., 1988) e no Quênia (Lima et al., 2005) também foi relatado maior ocorrência em ovinos, sugerindo que esse fato possa ocorrer devido ao processo de tosquia, a qual os animais do estudo não eram submetidos devido à ausência de lã. As variações da ocorrência nos diferentes estudos citados devem-se a diversidade dos sistemas de manejo, condições climáticas imunidade e grau de susceptibilidade dos animais (Al-Gaabary et al., 2009).

O principal agente envolvido em casos de abscessos em linfonodos de pequenos ruminantes é o C. pseudotuberculosis (Chirino-Zárraga et al., 2006), isolado em todas as amostras de secreção coletadas nesse estudo, assim como nas trinta amostras de caprinos criados em Sobral, Ceará (Lima et al., 2005). Em Sergipe, o agente já havia sido isolado em abscessos superficiais de ovinos de uma propriedade de Nossa Senhora da Glória e em região ventral das vértebras torácicas (T11 a T13) de reprodutor caprino, utilizado de maneira consorciada por quatro caprinocultores (Rizzo et al., 2014). O agente apresentou-se em alta ocorrência em ovinos da raça Santa Inês criados em Uberlândia, Minas Gerais onde houve crescimento de C. pseudotuberculosis em 81,8\% (18/22) dos abscessos investigados (Barbosa et al., 2012) e em amostras coletadas de linfonodos de ovinos abatidos no frigorífico de Mulungu, Paraíba, com isolamento do mesmo em 74,5\% (43/51) das secreções (Souza et al., 2011).

Os artigos citados anteriormente, assim como o presente estudo, objetivaram a investigação clínica de lesões sugestivas de LC em linfonodos 
superficiais, ressaltando-se que a real frequência da enfermidade pode estar subestimada, devido à possibilidade de acometimento de linfonodos viscerais, mais comum em ovinos, e a presença de animais sorologicamente positivos sem manifestação clínica (Guimarães et al., 2011), devido ao variado e amplo período de incubação (Belchior et al., 2006; Andrade et al., 2012). Apesar das evidências clínicas da LC nos animais dos rebanhos sergipanos e o isolamento do $C$. pseudotuberculosis em $100 \%$ das amostras, para que pudéssemos obter a real frequência da mesma fazia-se necessário que o conteúdo de todos os linfonodos, que se apresentaram clinicamente alterados, fossem submetidos ao diagnóstico bacteriológico (Chirino-Zarraga et al., 2006).

Estudo microbiológico pesquisando o $C$. pseudotuberculosis em linfonodos internos e vísceras de pequenos ruminantes abatidos em Alagoas, confirmou o envolvimento do agente em $46,15 \%$ (18/39) dos ovinos com sinais de abscessos isolando-o em amostras de pulmão, fígado, linfonodos, intestino delgado e grosso e 33,33\% (1/3) dos caprinos com o isolamento em amostra de intestino grosso (Jabour, 2013).

Deve-se também levar em consideração a possibilidade da ocorrência de outras causas que levam a alterações clínicas em linfonodos como: traumas, corpos estranhos, reações de sensibilidade às injeções e tumores que são diagnósticos diferenciais da LC (Belchior et al., 2006), assim como o aumento de volume devido processos inflamatórios ou infeciosos na região corpórea no qual o respectivo é responsável pela sua drenagem linfática, o que não foi observado nos animais do estudo. Outros agentes como; Actinomyces, Escherichia coli, Enterococcus sp., Estafilococcos, Pasteurella multocida, Pseudomonas aeruginosa, Staphylococcus aureus, Staphylococcus coagulase negativa, Streptococcus e Proteus mirabilis também podem estar envolvidos, mesmo em menor ocorrência, em casos de abscesso em linfonodos de pequenos ruminantes (Ribeiro et al., 2001; Andrade et al., 2012; Barbosa et al., 2012; AlGaabary et al., 2009; Jabour, 2013).

De acordo com a alta taxa observada de propriedades com animais de linfonodos reativos, sugere-se uma considerável disseminação do agente nos rebanhos sergipanos que apresentaram falhas importantes no manejo sanitário, como a baixa utilização da quarentena e desinfecção de instalações que propiciam respectivamente a entrada de animais enfermos devido ao variado período de incubação da LC e a manutenção da bactéria no ambiente por longos períodos (Brown e Olander, 1987; Belchior et al., 2006).

Em rebanhos criados em sistema semiextensivo e extensivo de Petrolina, Pernambuco a LC foi a principal enfermidade presente (Coelho et al., 2011), sistemas esses predominantes entre as propriedades desse estudo $(89,11 \%)$. Pesquisa em 147 rebanhos de caprinos e ovinos do Sertão do mesmo estado obteve relato da presença de abscessos cutâneos nos animais por 92,52\% (136/147) dos proprietários (Alencar et al., 2010), enquanto que no Rio Grande do Norte foi relatada em 98,5\% (65/66) das propriedades (Santos et al., 2013). Em 165 rebanhos Maranhenses (Teixeira et al., 2015), a presença de problemas sanitários relacionados à $\mathrm{LC}$ aparece em segundo lugar, com taxa de 84,14\% (69/82) para caprinos e 79,51\% (66/83) para ovinos, ficando atrás somente dos casos de verminose, enquanto no Piauí, em 64\% (29/45) das propriedades houve relato da presença da doença (Nascimento et al., 2011).

Essa alta ocorrência observada nos rebanhos pode ser influenciada pelo confinamento, presença de plantas cactáceas, utilização de pastagens nativas, procedimentos cirúrgicos, ausência de sistemas de controle nas fazendas, transporte e comercialização dos animais, empréstimos de reprodutores o que facilita a introdução e a disseminação do agente no rebanho (Souza et al., 2011; Rizzo et al., 2014; Andrade et al., 2012). Rebanhos em que os proprietários permitem que os abscessos se rompam naturalmente possuem maior chance de apresentar LC (Andrade et al., 2012), sendo assim nesse estudo foi realizado a drenagem e tratamento de 95 linfonodos abscedados, reduzindo seu poder infectante pois evitou-se que o mesmo supurasse espontaneamente contaminando o ambiente, além da introdução, no seu interior com manutenção por 24 horas, de gaze embebida com iodo a $2 \%$ com objetivo de reter possíveis secreções pós drenagem e cauterização química da capsula interna do abscesso.

Considerando a distribuição dos abscessos nos linfonodos superficiais, foi identificado que o pré-escapular foi mais acometido, seguido do submandibular, retromamário e pré-crural, corroborando com outros trabalhos como o realizado em rebanho de Nossa Senhora das Dores, Sergipe (Freitas et al., 2011) e das microrregiões de Piancó e Itaporanga na Paraíba (Andrade et al., 2012). Em exame post mortem de ovinos 
deslanados abatidos na Paraíba (Souza et al., 2011), a maior ocorrência de linfonodos reativos também foi o pré-escapular com $36,19 \%$, (97/268), assim como em ovinos da região de Uberlândia, MG (Barbosa et al., 2012. No Egito (Al-Gaabary et al., 2009) ocorreu maior predominância do linfonodo parotídeo (106/228) em ovinos, tendo o préescapular como o segundo maior afetado (87/228), seguido dos linfonodos mandibular e pré-crural. Em caprinos, somente o pré-escapular foi afetado.

Os linfonodos mais acometidos se encontravam na região de tronco e cabeça do corpo assim como relatado em rebanhos do Egito (AlGaabary et al., 2009) com 95,61\% (218/228) de ovinos e 100\% (45/45) dos caprinos com achados clínicos de LC. Isso pode ser justificado pelo fato de que os rebanhos de caprinos e ovinos provavelmente se infectam com maior facilidade pela via oral (Chirino-Zarraga et al., 2006; Ashfaq e Campbell, 1979) ou por pequenos traumatismos ocorridos na região anterior do corpo no momento do ramoneio em árvores e arbustos de folhas na caatinga ao utilizarem a posição bipedal para se alimentar (Souza et al., 2011), pois muitos dos rebanhos são criados de forma extensiva e semiextensiva. Pode haver influencia ainda, em ovinos lanados, o processo de tosquia que leva a pequenos ferimentos no tronco (Belchior et al., 2006).

Os caprinovinocultores do Estado devem estar atentos quanto às medidas profiláticas da LC, mesmo com a baixa ocorrência nesse estudo, uma vez que um animal infectado pode atuar como fonte de disseminação da doença a todo o rebanho. Devese realizar a inspeção frequente de todo o rebanho para a identificação e isolamento de animais com manifestação clínica da enfermidade para posterior drenagem do abscesso, adoção de quarentena, higiene e desinfecções das instalações e controle de moscas (Brown e Olander, 1987; Belchior et al., 2006).

\section{Conclusão}

As evidências clínicas da infecção e o isolamento do C. pseudotuberculosis, observadas nos rebanhos de pequenos ruminantes sergipanos, associada as falhas no manejo sanitário, alertam quanto à potencialidade de disseminação do agente se não adotada medidas de tratamento e profilaxia da enfermidade.

\section{Conflito de Interesse}

Os autores declaram não existir conflito de interesse.

\section{Comitê de Ética}

Todos os procedimentos utilizados nesse estudo foram aprovados pela Comissão de Bioética da Faculdade Pio Décimo, Aracaju, SE número 06/2011.

\section{Agradecimentos}

Ao Grupo de Iniciação Científica e Extensão em Buiatria (GICEB) da Faculdade Pio Décimo de Aracaju, Sergipe pela coleta dos dados desse artigo.

\section{Referências}

Alencar, S.P.; Mota, R.A.; Coelho, M.C.O.C.; Nascimento, S.A. Abreu, S.R.O.; Castro, R.S. Perfil sanitário dos rebanhos caprinos e ovinos no sertão de Pernambuco. Ciência Animal Brasileira, 11(1): 131-140, 2010.

Al-Gaabary, M.H.; Osman, A.S.; Oreiby, A.F. Caseous lymphadenitis in sheep and goats: clinical, epidemiological and preventive studies. Small Ruminant Research, 87: 16121, 2009.

Andrade, J.S.L.; Azevedo, S.S.; Teles, J.A.A.; Higino, S.S.S.; Azevedo, E.O. Ocorrência e fatores de risco associados à infecção por Corynebacterium pseudotuberculosis em caprinos e ovinos do semiárido paraibano. Pesquisa Veterinária Brasileira, 32(2): 116-120, 2012.

Ashfaq, M.K., Campbell, S.G. A survey of caseous lymphadenitis and its etiology in goats in the United States. Veterinary Medicine Small Animal Clinician, 74(8): 1161-1165, 1979.

Barbosa, V.M.; Antunes, U.C.; Silva, N.C.; Gondim, C.C; Nasciutti, N.R.; Nassar, A.F.C.; Miyashiro, S.; Saut, J.P.E. Ocorrência de linfadenite caseosa em ovinos da raça Santa Inês com linfonodos superficiais reativos na região de Uberlândia, Minas Gerais. Boletim de Indústria Animal, 69(2): 109-115, 2012.

Belchior, S.E.; Gallardo, A.; Ábalos, A.; Jodor, N.; Jensen, O. Actualización sobre linfoadenitis caseosa: el agente etiológico y la enfermedad. Veterinaria Argentina, 23(224): 258-278, 2006. 
Brown, C.C.; Olander, H.J. Caseous lymphadenitis of goats and sheep: a review. Veterinary Bulletin, 57: 7445-7448, 1987.

Chirino-Zárraga, C.; Scaramelli, A.; Rey-Valeirón, C. Bacteriological characterization of Corynebacterium pseudotuberculosis in Venezuelan goat flocks. Small Ruminant Research, 65(1-2): 170-175, 2006.

Coelho, M.C.S.C; De Souza, V.C.; Coelho, M.I.S.; Cunha, M.P.; Medina, F.T. Aspectos sanitários de rebanhos caprinos e ovinos criados em assentamentos no município de Petrolina-PE. Revista Semiárido De Visu, 11(1): 32-40, 2011.

Freitas, L.M.D.; De Jesus, I.B.; Barbosa, C.S.S.; Vieira, R.T.A.; Rizzo, H. Incidência de Linfadenite Caseosa em ovinos, da raça Santa Inês, na Fazenda Formosa, em Nossa Senhora das Dores, município de Sergipe. In: CONGRESSO NORDESTINO DE PRODUÇÃO ANIMAL, 6, 2011, Mossoró. Anais ... Mossoró, 2011.

Getty, R. Anatomia dos animais domésticos, Sisson \& Grossmann. 1 e 2 vol. Rio de Janeiro (Brasil): Interamericana; 1981.

Guimarães, A.S.; Carmo, F.B.; Pauletti, R.B.; Seyffert, N.; Ribeiro, D.; Lage, A.P.; Heinemann, M.B.; Miyoshi, A.; Azevedo, V.; Gouveia, A.M.G. Caseous lymphadenitis: epidemiology, diagnosis, and control. The IIOAB Journal, 2(2): 3343, 2011.

IBGE - Instituto Brasileiro de Geografia e Estatística. Bases cartográficas. 2014. Disponível em: http://geoftp.ibge.gov.br/organizacao_do_te rritorio/malhas_territoriais/malhas_municip ais/municipio_2014/SE/>. Acesso em: 20 jun. 16.

IBGE - Instituto Brasileiro de Geografia e Estatística. Dados epidemiológicos de Sergipe. 2015. Disponível em: <http://www.ibge.gov.br/estadosat/perfil.ph p?sigla=se\#>. Acesso em: 19 set. 2015.

Jabour, F.F. Diagnóstico de micobacterioses e linfadenite caseosa em ovinos e caprinos no Leste Alagoano. 2013. 100 f. Tese (Doutorado), Ciência Veterinária, Universidade Federal Rural de Pernambuco, Recife, 2013.
Lima, F.W.C.; Frota, I.M.A.; Sousa, F.G.C.; Andrade, J.T.F.; Alves, F.S.F. Análise bacteriológica de abscessos cutâneos em caprinos. In: ENCONTRO DE INICIAÇÃO CIENTÍFICA DA UNIVERSIDADE DO VALE DO ACARAÚ, 7, 2005, Sobral. Anais ... Sobral, 2005. p. 3.

Machado, G.; Gressler, L.T.; Kirinus, J.K.; Herrmann, G.P. Linfadenite caseosa em ovinos abatidos sob inspeção federal no estado do Rio Grande do Sul - estimativas de perdas. Acta Scientiae Veterinariae, 39(2): 1-6, 2011.

Moura Costa M.D.; Câmara J.Q.; Rocha J.V.N.; Martinez T.C.N. Linfadenite caseosa dos caprinos no Estado da Bahia. Distribuição geográfica da doença. Boletim do Instituto Biológico da Bahia, 12(1),:1-7, 1973

Nuttall, W. Caseous lymphadenitis in sheep and goats in New Zealand. Surveillance, 15(1): 10-12, 1988.

Pugh, D.G. Sheep \& Goat Medicine. In: Diffay, B.C.; Mckenzie, D.; Wolf, C.; Pugh, D.C. Handling and examination of sheep and goat. Philadelphia: Saunders, 2005. p.8-24.

Ribeiro, M.G.; Dias Junior, Barbosa, P. G; Nardi Júnior, G.; Listoni, F.J.P. Punção aspirativa com agulha fina no diagnóstico do Corynebacterium pseudotuberculosis na Linfadenite Caseosa caprina. Arquivos do Instituto Biológico, 68(1): 23-28, 2001.

Rizzo, H.; Carvalho, J.S.; Fraga, G.J.M.; Lauria, M.J.S.; Languidey, P.H. Paralisia de membros pélvicos em reprodutor caprino causada por Linfadenite Caseosa no Estado de Sergipe. Pubvet, 8(22), Ed. 271, Art. 1812, 2014.

Santos, V.W.S.; Santiago, L.B.; Alves, F.S.F; Farias, D.A.; Lima, A.M.C.; Pinheiro, R.R. Aspectos sanitários da caprinocultura e ovinocultura no estado do Rio Grande do Norte. In: ENCONTRO DE INICIAÇÃO CIENTÍFICA E VIII ENCONTRO DE PÓS-GRADUAÇÃO E PESQUISA DA UNIVERSIDADE ESTADUAL VALE DO ACARAÚ, 15, 2013, Anais ... Sobral, 2013. p. 3 .

Silva, R.A.B.; Batista, M.C.S.; Nascimento, C.B.; Alves, R.P.A.; Alves, F.S.F.; Pinheiro, R.R.; Sousa, M.S.; Diniz, B.L.M.; Cardoso, J.F.S.; Paula, N.R.O. Caracterização zoosanitária da ovinocultura e da caprinocultura na 
microrregião homogênea de Teresina, Piauí, Brasil. Arquivos do Instituto Biológico, 78(4): 593-598, 2011.

Souza, M.F.; Carvalho, A.Q.; Garino Júnior, F.; Riet-Correa, F. Linfadenite caseosa em ovinos deslanados abatidos em frigorífico da Paraíba. Pesquisa Veterinária Brasileira, 31(3): 224-230, 2011.

Teixeira, W.C.; Santos, H.P.; Silva, J.C.R.; Rizzo, H.; Marvulo, M.F.V.; Castro, R.S. Perfil sanitário dos rebanhos caprinos e ovinos em três mesorregiões do Estado do Maranhão, Brasil. Acta Veterinaria Brasilica, 9(1): 34-42, 2015.

Winn, W.C.; Allen, S.D.; Janda, W.M.; Koneman, E.W.; Procop, G.W.; Schreckenberger, P.C.; Woods, G.L. Koneman, diagnóstico microbiológico: texto e atlas colorido. Rio de Janeiro (Brasil): Guanabara Koogan, 2008. Bacilos Gram-positivos aeróbicos e facultativos. p. 760-851. 